This is an electronic version of an article published in Tellus B:

complete citation information for the final version of the paper, as published in the print edition of Tellus B, is available on the Blackwell Synergy online delivery service, accessible via the journal's website at http://www.blackwellpublishing.com/journals/TEB or http://www.blackwell-synergy.com 


\title{
Alpine ice cores and ground penetrating radar: combined investigations for glaciological and climatic interpretations of a cold Alpine ice body
}

\author{
By OLAF EISEN ${ }^{1 *}$, UWE NIXDORF ${ }^{1}$, LOTHAR KECK $^{2}$ and DIETMAR WAGENBACH ${ }^{2},{ }^{1}$ Alfred- \\ Wegener-Institut für Polar- und Meeresforschung Bremerhaven, Bremerhaven, Germany; ${ }^{2}$ Institut für \\ Umweltphysik, Universität Heidelberg, Heidelberg, Germany
}

(Manuscript received 13 November 2002; in original form 22 April 2003)

\begin{abstract}
Accurate interpretation of ice cores as climate archives requires detailed knowledge of their past and present geophysical environment. Different techniques facilitate the determination and reconstruction of glaciological settings surrounding the drilling location. During the ALPCLIM ${ }^{1}$ project, two ice cores containing long-term climate information were retrieved from Colle Gnifetti, Swiss-Italian Alps. Here, we investigate the potential of ground penetrating radar (GPR) surveys, in conjuction with ice core data, to obtain information about the internal structure of the cold Alpine ice body to improve climatic interpretations. Three drill sites are connected by GPR profiles, running parallel and perpendicular to the flow line, thus yielding a three-dimensional picture of the subsurface and enabling the tracking of internal reflection horizons between the locations. As the observed reflections are of isochronic origin, they permit the transfer of age-depth relations between the ice cores. The accuracy of the GPR results is estimated by comparison of transferred timescales with original core datings, independent information from an older ice core, and, based on glaciological surface data, findings from flow modeling. Our study demonstrates that GPR is a mandatory tool for Alpine ice core studies, as it permits mapping of major transitions in physical-chemical properties, transfer of age-depth relations between sites, correlate signals in core records for interpretation, and establish a detailed picture of the flow regime surrounding the climate archive.
\end{abstract}

\section{Introduction}

Ice cores from mid-latitude cold glaciers can provide unique records of environmental and climate changes which are important to supplement respective paleo-information commonly retrieved from polar drill sites (Wagenbach, 1989). However, alpine icecore data are much more difficult to interpret in terms of their underlying atmospheric signals than their polar counterparts. One of various shortcomings is the fact that the length scales over which dynamic changes can

\footnotetext{
${ }^{*}$ Corresponding author address: Alfred-Wegener-Institut für Polar- und Meeresforschung, Postfach 120161, 27515 Bremerhaven, Germany. e-mail: oeisen@awi-bremerhaven.de
}

occur are much smaller than in polar settings, such that there can be significant changes in glaciological boundary conditions (i.e. glacier thickness, surface and bedrock topography, firn/ice transition depth and net snow accumulation rate) (Vincent et al., 1997) that occur over short distances. In Alpine ice core studies, apart from very exceptional dome drill positions, upstream effects have to be considered carefully to ensure reliable extraction of the net atmospheric change from the isotopic $\left(\delta^{18} \mathrm{O}, \delta \mathrm{D}\right)$ and chemical (aerosolrelated species, entrapped trace gases) ice core records (Wagenbach, 1994). Inflow of material deposited upstream of the borehole may thus systematically affect

\footnotetext{
${ }^{1}$ Environmental and Climate Records from High Elevation Alpine Glaciers.
} 
the vertical temperature distribution, flow model based dating, the enclosure of trace gases, and, most important, the impurity and isotope depth profile (Preunkert et al., 2000). Evaluation of such upstream effects needs extensive work including establishment of back trajectories from ice flow modeling along with secondary ice core investigations in the relevant catchment area of the main drill position.

In this context, ground penetrating radar (GPR) provides a powerful tool to map the glacier thickness distribution needed for ice flow modeling. GPR may also be used to establish the stratigraphy of internal radar reflection horizons (Bogorodsky et al., 1985), which are expected, in favourable cases like undisturbed layering and absence of percolation, to indicate isochronic layers. Such GPR-based mapping of englacial isochrones may be used to depict the spatial accumulation and vertical strain rates distribution on a quasi-continuous scale. This feature would greatly help to verify the flow regime, encountered upstream effects and the matching of ice core chronologies obtained in the drill site area of interest. Whereas GPR sounding of glacier thickness is routinely deployed at polar and alpine sites, continuous internal radar reflector mapping has been accomplished so far mostly on polar and subpolar ice sheets by large-scale tracking of (presumably) acidic volcano horizons (e.g. Millar, 1981; Siegert, 1999; Hempel et al., 2000), but only very few studies investigated the internal structure of glaciers by combination of ice core data and radar profiles (Pälli et al., 2002).

Here we present a GPR study on a cold Alpine glacier saddle (Colle Gnifetti, Swiss-Italian Alps) aimed at assessing the potential for using englacial reflectors to track layers within the drill site area. Colle Gnifetti, which constitutes the key site for longterm ice-core records from the Alps, has been investigated through several glaciological and ice-core drilling projects (Döscher et al., 1995). Hence, basic information on glacier flow, age-depth relation, and vertical distribution of physical and chemical properties has been partially available. With respect to the latter, almost all mountain drill sites differ significantly from polar ones through the much larger depth fraction made up by porous firn, the prominent occurrence of melt layers (i.e. higher density variability), and the much higher and more variable impurity content. Thus, the study is focused on determining to what extent the interaction of GPR signals with a particular glacial feature may provide useful statigraphic information.

\section{Glaciological and glacio-chemical settings}

The Colle Gnifetti is a small glacier saddle within the summit range of Monte Rosa (Swiss-Italian Alps) lying at $4450-4560 \mathrm{~m}$ a.s.l., and is the uppermost accumulation area of Grenzgletscher. Due to its exposed position, wind erosion controls its net annual snow accumulation, which therefore reflects only about $10 \%$ the mean precipitation rate measured further downglacier (Alean et al., 1983). Almost all ice core activities took place in the southern part of the saddle, which provides a relatively low annual snow accumulation. Three ice cores were drilled to bedrock along a common surface flow line (Fig. 1).
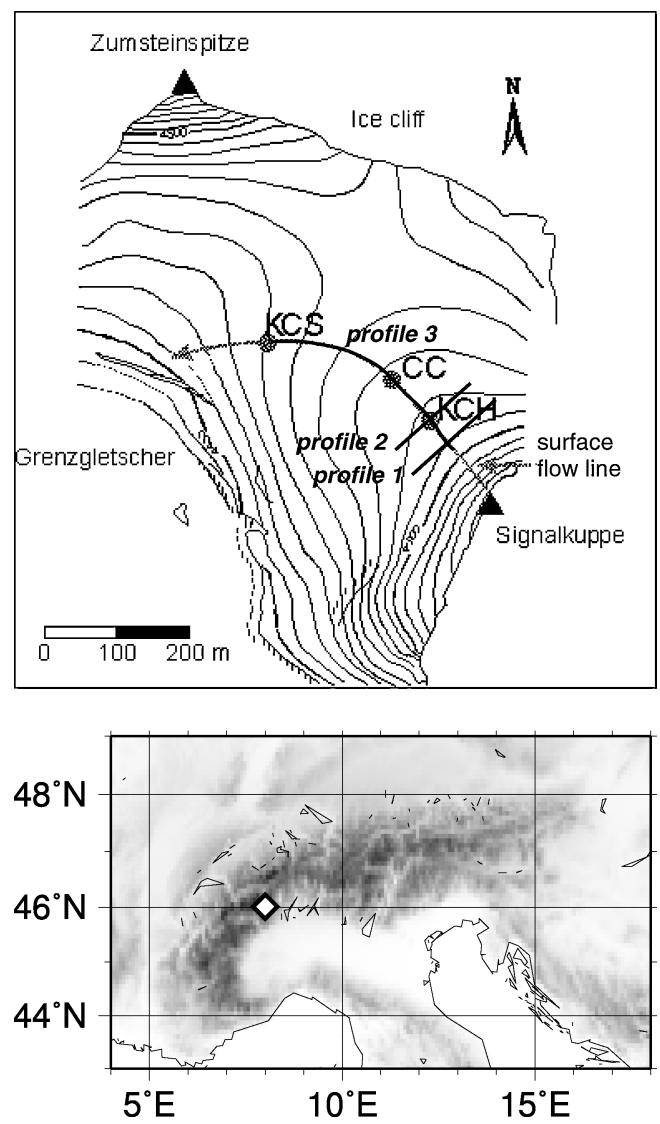

Fig. 1. Surface topography of southern Colle Gnifetti flank showing the location of deep ice core positions and GPR profiles $1-3$. Contour lines refer to $10 \mathrm{~m}$ altitude steps. The white diamond in the lower topographic map indicates the location of the study area in the European Alps. 
Table 1. Basic glaciological parameters observed along a flow line at Colle Gnifetti

\begin{tabular}{|c|c|}
\hline Characteristic & Description \& reference \\
\hline Snow zone characterisation & $\begin{array}{l}\text { Cold infiltration-recrystallisation zone, associated with occasional melt-layer } \\
\text { formation at a downslope decreasing rate (after Shumskii, 1964) }\end{array}$ \\
\hline Englacial temperature & $\begin{array}{l}18 \mathrm{~m} \text { firn temperature }-14.3^{\circ} \mathrm{C} \text { (Suter, 20002) } \\
\text { basal temperature }-12.3^{\circ} \mathrm{C} \text { (Haeberli and Funk, 1991) }\end{array}$ \\
\hline Glacier thickness & $\begin{array}{l}\text { Systematically decreasing from about } 140 \mathrm{~m} \text { in the lower area to } \sim 50 \mathrm{~m} \\
\text { in the upper area (this study, Haeberli and Funk, 1991; Lüthi, 2000) }\end{array}$ \\
\hline Annual snow accumulation & $\begin{array}{l}\text { Systematically decreasing from around } 60 \mathrm{~cm} \text { water equivalent (WE) } \\
\text { at KCS borehole to } 20 \mathrm{~cm} \mathrm{WE} \text { at the upper } \mathrm{KCH} \text { positions (Keck, 2001) }\end{array}$ \\
\hline Horizontal surface velocity & $\begin{array}{l}\text { Systematically decreasing from } 2 \mathrm{~m} \mathrm{a}^{-1} \text { in the lower area to less than } \\
1 \mathrm{~m} \mathrm{a}^{-1} \text { in the upper area (Lüthi, 2000) }\end{array}$ \\
\hline Firn-ice transition depth & $\begin{array}{l}\text { Around } 45 \text { and } 36 \mathrm{~m} \text { at the KCS and KCH borehole positions, } \\
\text { respectively (Keck, 2001) }\end{array}$ \\
\hline
\end{tabular}

In this area, detailed surface velocity and accumulation rate data were obtained from multi-year geodetic observations of a stake array and additional shallow ice core drillings (Keck, 2001; Lüthi, 2000). As shown in Fig. 1, the present GPR study was mainly dedicated to the area associated with the three deep drillings. The typical glaciological parameters encountered in the GPR mapped area are summarised in Table 1.

Ice core chronologies deployed in this study were established by annual layer counting from major ions stratigraphy, which was backed up by absolute time horizons from extreme Saharan dust deposits [1977, 1936, 1902 (Armbruster, 2000)] and thermo-nuclear bomb tests (1963). As is the case for all alpine drill sites exposed to strong wind scouring and thus low and irregular snow deposition, dating by annual layer counting and preservation of stratigraphical horizons remains ambiguous at Colle Gnifetti. Furthermore, dating uncertainty increases dramatically with depth due to annual layer thinning and the associated nonlinear age-depth relationship.

The chemical composition of Colle Gnifetti ice cores may be characterised as follows:

There are highly variable mineral dust levels with a background around $0.55 \mathrm{mg} \mathrm{kg}^{-1}$, strongly enhanced on a multi-annual timescale by Saharan dust layers to some $10 \mathrm{mg} \mathrm{kg}^{-1}$ (Wagenbach et al., 1996). Significant inputs of acidity aerosol components (sulfate, nitrate) mainly occurred since 1950 , corresponding to about 20-40 m depth in the study area. During that period, mostly annual peaks are seen, which exceed the background values of around 140 and $180 \mu \mathrm{g} \mathrm{kg}^{-1}$ for sulfate and nitrate, respectively, by up to a factor of 20 (Maupetit et al., 1995).
Strong acidic horizons are known to produce GPR reflections (Bogorodsky et al., 1985). Colle Gnifetti displays high-frequency acidic spikes roughly on an annual timescale during the industrial era (Preunkert et al., 2001). This pattern is, however, strongly disturbed by the distinct but irregular inputs of alkaline dust and the preferential erosion of relatively clean snow of the winter half year. Thus, the chemical stratigraphy of potential acidic layers in the industrial era displays a rather erratic structure with distinct peaks emerging in sub-seasonal to multi-annual sequences.

From the continuous chemical depth profiles available from all three ice cores, we used the following parameters to contrast the chemical stratigraphy with the GPR based reflector pattern: $\mathrm{Ca}^{2+}$ as proxy for the total mineral dust content, as it controls the insoluble particulate matter and melt water alkalinity of the ice matrix; the positive values of the ion balance reduced to $\left(\mathrm{SO}_{4}^{2-}+\mathrm{NO}_{3}^{-}-\mathrm{Ca}^{2+}-\mathrm{NH}_{4}^{+}\right)$to illustrate the variability of apparent meltwater acidity. Note that negative numbers of this parameter are redundant since they virtually reproduce the pattern of the calcium concentration.

\section{GPR methodology}

Ice-core records and GPR data provide mutual information on glacial subsurface structure and composition. Whereas ice cores yield vertical profiles of physical features (density, crystal fabric properties, etc.) and chemical impurities in a one-dimensional resolution on a centi- to decimetre depth scale, analyses of GPR data result in two-dimensional pictures of the 
subsurface structure of the ice body. Although horizontal and vertical changes on the order of metres can be extracted from GPR data, it is, in general, not possible to identify unambiguously the causes of the obtained structures by this method. The combination of ice-core records and GPR data may thus help to extrapolate ice-core information along GPR profiles, resulting in a two-dimensional picture of the physical and chemical properties of the subsurfaces. This is limited, however, by the lateral coherency of the observed signal and the depth resolution of the GPR data.

To link ice cores, it is necessary to track continuous internal layers. In general, an electromagnetic (EM) pulse is transmitted at the surface and the propagating wave is partially reflected at discontinuities of the medium's dielectric properties (i.e. permittivity and conductivity) (Robin et al., 1969), and the reflected signals are recorded at the surface as a function of twoway travel time (TWT). The resulting image of the subsurface is referred to as the time domain radargram.

In a cold alpine ice body, discontinuities in the dielectric properties are expected to be mainly related to the occurence of ice layers in the firn and to significant impurity horizons (e.g. acidic spikes). The processes forming EM reflectors take place at the glacier's surface at approximately the same time, implying that the internal reflectors are isochrones, with the submergence rate being determined by the interaction of the surface accumulation and the flow field.

\subsection{Survey setups and data acquisition}

Two types of measurement are common in GPR data acquisition: common-offset $(\mathrm{CO})$ and commonmidpoint (CMP) surveys. For CO surveys, the transmitter (TX) and receiver (RX) are kept at a fixed distance and moved across the surface. For the CMP recording technique, the distance between TX and RX is symmetrically increased relative to the stationary centre point, basically yielding information about the wave speed-depth profile. This method is a standard tool in seismic data acquisition (Garotta and Michon, 1967; Yilmaz, 1987), and has also been applied successfully in modified versions to glaciological GPR surveys (Gudmandsen, 1971; Hempel et al., 2000; Murray et al., 2000).

Radar measurements were performed with a RAMAC GPR (Malå Geoscience, Sweden), a monopulse bistatic radar system that can be operated with antennae of different frequencies. $\mathrm{CO}$ measurements were carried out with shielded $250 \mathrm{MHz}$ anten- nae, which are permanently mounted in a sled box at a fixed distance of $36 \mathrm{~cm}$. The common-midpoint survey was carried out with a pair of unshielded antennae operating at a centre frequency of $100 \mathrm{MHz}$. For either system setup the TX and RX are connected with the central processing unit via fibre optic cables, thus avoiding noise from ohmic conductors. The processing unit was operated by a Husky FC PX5 personal computer, using RAMAC software.

Three CO profiles were measured along the three profile lines 1-3 (Fig. 1), which were already marked with geodetic stakes. The transmitter was triggered by a distance wheel, mounted at the rear of the sled box, and set to a trigger interval of $0.5 \mathrm{~m}$. Trace length was $1.5 \mu$ s with 2048 samples per trace. To increase the signal-to-noise ratio, 32-fold vertical stacking was applied for each stored trace.

For the CMP survey, the $\mathrm{KCH}$ borehole was chosen as the centre point, and TX-RX offset was increased along profile 2, perpendicular to the flow line. Traces were recorded in a $1.5 \mu$ s time window with 2048 samples and 256-fold vertical stacking, manually triggered in $1 \mathrm{~m}$ increments in the interval 1 to $100 \mathrm{~m}$.

\subsection{Post-recording processing}

Processing was performed using Paradigm Geophysical FOCUS version 4.2 software. Standard postrecording processing for $\mathrm{CMP}$ and $\mathrm{CO}$ data includes filtering and gain correction. CMP data are then analysed in the time domain, resulting in a TWT-depth model. The major processing steps for $\mathrm{CO}$ surveys are migration and TWT-depth conversion, each requiring a profile of propagation wave speed.

In the present study it was not feasable to apply postrecording horizontal stacking of neighbouring traces, usually used to decrease noise, because of the steep internal and bottom features. Although stacking was successful in the upper few metres, the coherency of internal reflectors at greater depth decreased, thus making it more difficult to track continuous internal reflections. For further processing, the data were, therefore, only bandpass filtered, and the recording position (accurate to $\sim 1 \%$ ) assigned to each trace. Based on the comparison of TWT-depth profiles derived from the CMP survey and ice-core data, discussed below, migration of the $\mathrm{CO}$ profiles and conversion to depth domain was carried out using the interpolated TWT-depth model determined from the ice core density profiles at KCS and $\mathrm{KCH}$. The same $\mathrm{CO}$ processing sequence was applied to all three $\mathrm{CO}$ profiles, resulting in a picture of the subsurface and bedrock structure (Fig. 2). 


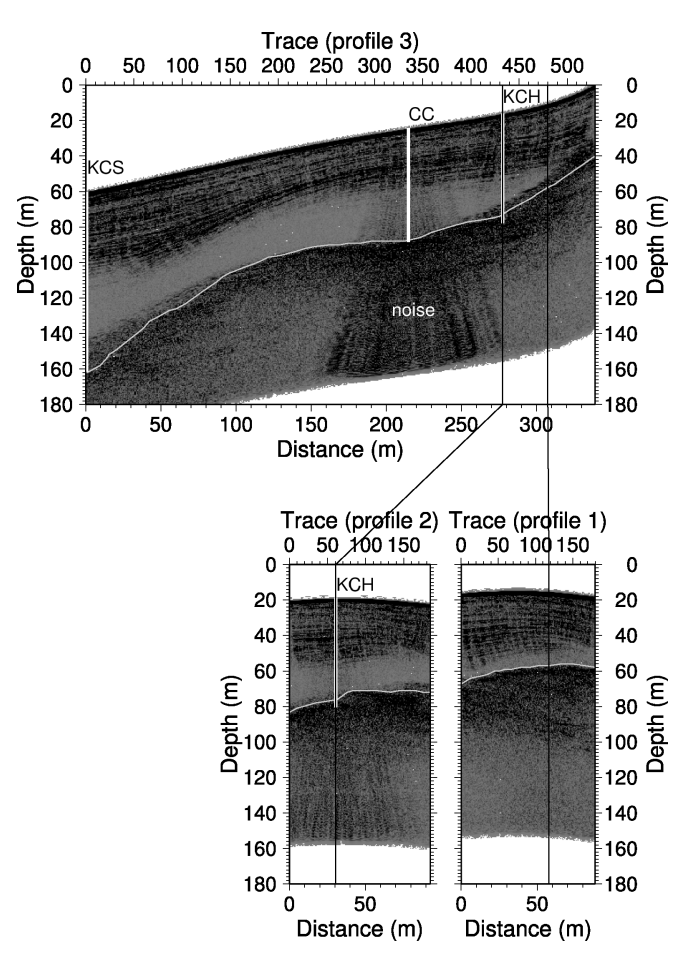

Fig. 2. Processed radar profiles indicating surface and bedrock topography (light grey) in metres below $4500 \mathrm{~m}$ a.s.1. along profiles 1-3. Greyscale indicates trace envelope. Location and extent of the KCS, $\mathrm{CC}$ and $\mathrm{KCH}$ boreholes are indicated as white vertical bars, crossover points of profiles as thin black lines. Bedrock depths were determined by strongly enlarging the processed data and applying a colour amplitude scaling. The noise centred at a distance of $220 \mathrm{~m}$ (approximately near CC) below $100 \mathrm{~m}$ depth probably results from scattered metal remains buried underneath the surface.

\section{GPR and Ice Cores}

An essential aim of our study is to investigate the possibility to transfer age-depth relations from one ice core to another using GPR data by analysing the structure of internal reflections. Before linking radargrams to ice-core records, we perform two comparisons to estimate errors of either data set and to limit the effect of ambiguities arising in the travel time versus depth profiles and ice thickness results.

\subsection{Travel time - depth profiles}

Apart from CMP surveys, EM propagation wave speeds can also be derived from ice-core records, e.g. dielectric profiling (DEP) (Moore and Paren, 1987;
Wilhelms, 2000) or density (Looyenga, 1965; Robin et al., 1969). Using the KCS and KCH density profiles, we apply the Looyenga (1965) mixture model for calculating two interval wave speed-depth profiles. The $\mathrm{CMP}$ wave-speed model at $\mathrm{KCH}$ is based on the analysis of five internal and one bottom reflectors.

The interval wave speeds are systematically higher for the CMP than for the density-derived profile (Fig. 3b). This leads to $\sim 10 \%$ larger depth of the CMP model for the same TWT compared to the density based model (Fig. 3c). Reasons for the systematic differences of both data sets are investigated in the discussion. As wave speed profiles derived from different physical properties of ice cores (e.g. $\gamma$-ray absorption or permittivity) are more consistent than those based on CMP surveys (Eisen et al., 2002), we use the TWTdepth relations from $\mathrm{KCS}$ and $\mathrm{KCH}$ for migration and conversion of the radargrams to the depth domain.

\subsection{Bedrock topography}

In theory, the depth of a perfect plane reflector should be identifiable within a quarter of the wavelengths, i.e. 0.2 and $0.4 \mathrm{~m}$ for the 250 and $100 \mathrm{MHz}$ antennae, respectively. However, the rough nature of the bed, a non-planar curvature, and uncertainties in the wave speed-depth distribution decrease the accuracy with which the bed topography can be determined. The bedrock topography can be extracted from highresolution $\mathrm{CO}$ profiles (Fig. 2), and for $\mathrm{KCH}$ also from the CMP data (Fig. 3). Especially in those parts of the $\mathrm{CO}$ profiles with steep bedrock topography the bed reflection is blear, and can only be determined with an accuracy of approximately $\pm 5 \mathrm{~m}$. In the other parts it is clearly identifiable to within $2 \mathrm{~m}$. Ice thickness derived from CO data is $102 \pm 5 \mathrm{~m}$ at $\mathrm{KCS}$, and $58 \pm 5 \mathrm{~m}$ at $\mathrm{KCH}$ (Table 2). The depths at the crossing points of surveys are within $4 \mathrm{~m}$ of each other. The ice thickness derived from the CMP measurements at $\mathrm{KCH}$ is $60 \pm$ $2 \mathrm{~m}$.

Additional information on ice thickness is available from earlier GPR surveys (Wagner, 1996; Lüthi, 2000) and borehole depths. Drilling was stopped when the amount of debris in the retrieved ice core increased, indicating that the basal layer was reached. Logged depths at KCS and KCH in 1995 are 101 and 61 m, respectively (Lüthi, 2000). Based on these data and flow modeling for conversion of the 1995 data to the 2000 surface, the KCS and $\mathrm{KCH}$ borehole bottoms should be located at depths of 101.3 and $61.7 \mathrm{~m}$, respectively (Table 2). 
(a)

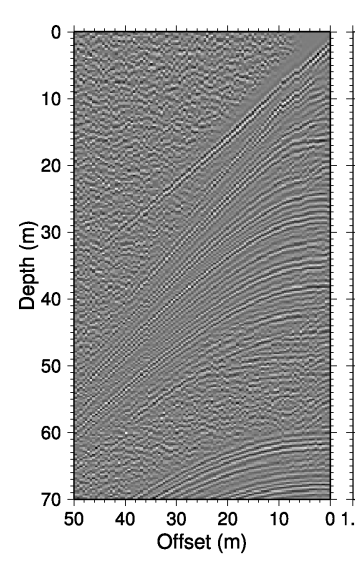

(b)

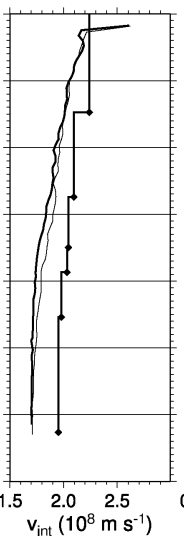

(c)

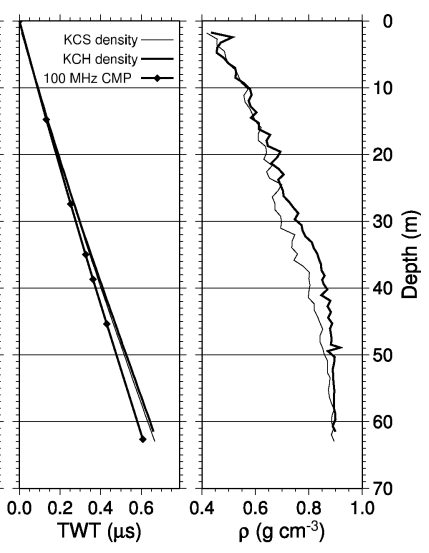

Fig. 3. Comparison of TWT-depth profiles at KCH drill site position, derived from ice-core density and common-midpoint (CMP) measurements. For the sake of completeness, the profiles derived from KCS ice-core density are displayed as well. (a) $100 \mathrm{MHz}$ CMP radargram; (b) depth profile of interval wave speed $v_{\text {int }}$; (c) depth profile of two-way traveltime (TWT); (d) depth profile of smoothed density $\rho$.

Table 2. Comparison of ice-core and GPR-based data on ice thicknesses at Colle Gnifetti

\begin{tabular}{lcccl}
\hline Data set & KCS & KCH & $\mathrm{X}_{1,3}$ & \multicolumn{1}{c}{ Remarks } \\
\hline $\begin{array}{l}\text { Borehole data and flow } \\
\text { Core length }\end{array}$ & 99.9 & 60.3 & - & Core top $\sim 0.6$ m below surface \\
$\begin{array}{l}\text { Logged depth } \\
\text { Bottom depth }\end{array}$ & 101 & 61 & - & After drilling (Lüthi, 2000, p. 40) \\
GPR ice thickness & 101.3 & 61.7 & - & Flow modeling (Keck, 2001) \\
CMP & - & $60(2)$ & & \\
Profile 1 & - & - & $42(2)$ & \\
Profile 2 & - & $58(2)$ & & \\
Profile 3 & $102(5)$ & $58(5)$ & $46(5)$ & \\
\hline
\end{tabular}

Core and GPR depths are given in metres with respect to the 2000 surface. Accuracies of GPR ice thickness values are given in parantheses. $\mathrm{X}_{1,3}$ denotes the crossover point of profiles 1 and 3.

\subsection{Internal structure and ice-core profiles}

A straightforward apportionment of individual internal reflectors to outstanding physical or chemical events seen in the ice cores is not feasible. This may have been expected in view of the uncertainty in the individual absolute depth scales but also in view of the relatively high frequency with which the potentially radar active features like acid spikes, melt layers etc. occur in alpine ice cores. Nevertheless, the matching of ice-core records via GPR profiles can be achieved.

The drilling locations $\mathrm{KCH}$ and $\mathrm{KCS}$ are connected via GPR profile 3 (Fig. 4). To determine the accuracy of a timescale transfer from one core to another, we (i) associate absolute time horizons at KCS to strong corresponding phases of an internal reflector at the same depths; (ii) track and mark continuous coherent phases from $\mathrm{KCS}$ to $\mathrm{KCH}$ in a large-scale, highresolution plot of the radargram; and (iii) compare the transferred age-depth relation to the chronology of $\mathrm{KCH}$.

The transmitted radar pulse consists of approximately five half-cycles, with the main energy being located in the first three. During propagation, the pulse is subject to phase shifts, distortions and multiple reflections. Therefore, in the recorded radargram, an internal reflector does not consist of a single maximum peak, but of several phases. In the migrated depth domain radargram, each phase is then on the order of $\lambda / 2$ 


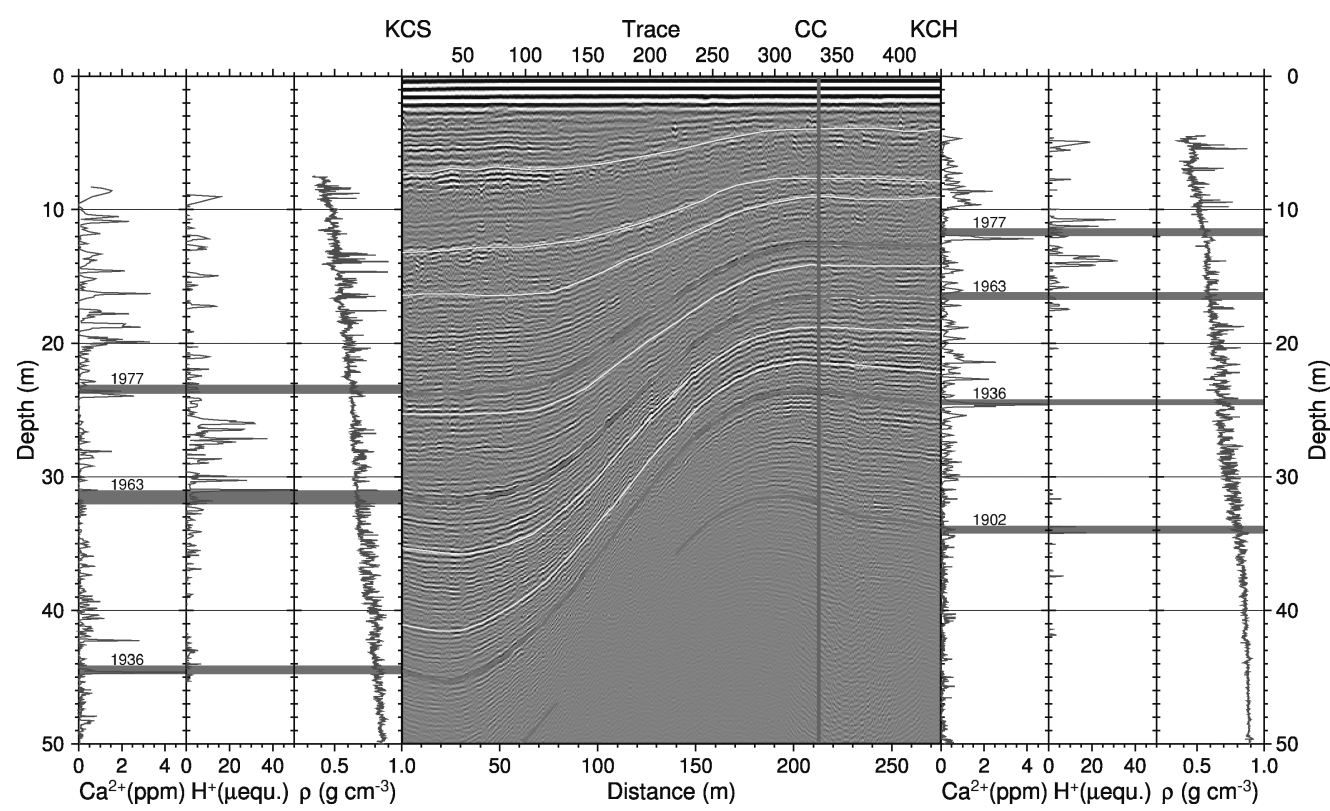

Fig. 4. Comparison of ice core profiles from KCS (left), $\mathrm{KCH}$ (right), with internal GPR reflectors along connecting profile 3 (middle). Recorded are calcium, serving as proxy for the total mineral dust content, ice acidity, and high-resolution densities (determined from $\gamma$-ray absorption), indicating the melt layer stratigraphy. Horizontal grey lines overlying the ice core records mark the depth of the 1902, 1936, 1963 and 1977 dating horizons. Thick white lines in the radargram indicate the depth of the dating horizons determined from tracking coherent phases starting from KCS; thin white lines mark strong continuous reflectors (see text for details). The white line to the 1902 horizon is interrupted because of the reflector discontinuity.

( $0.4 \mathrm{~m}$ in ice), and a sharp reflector is distributed over a depth range of approximately $2 \lambda$ (1.6 $\mathrm{m}$ in ice).

The radargram between KCS and $\mathrm{KCH}$ (Fig. 4) shows a smooth sigmoidal decrease left to right in the apparent accumulation rate, which is related to the bedrock topography (Fig. 2) via the ice flow field (Keck, 2001). About $100 \mathrm{~m}$ upslope of KCS, in the steepest part of the internal slope, the reflectors become discontinuous below a depth of $35 \mathrm{~m}$.

Starting the tracking of internal horizons at KCS yields a higher accuracy, as the annual layer thickness, and therefore temporal resolution, is almost twice as large as at $\mathrm{KCH}$. Tracking the reflectors corresponding to the 1936, 1963 and 1977 data from KCS to $\mathrm{KCH}$ results in depths that are about $0.8-1.0 \mathrm{~m}$ lower than the respective data in the $\mathrm{KCH}$ ice core profiles (Table 3). The last continuous reflector corresponds to about 1930. Older dating horizons, in particular the 1902 event, cannot be used for tracking without significantly decreasing the accuracy because of discontinuities of the GPR horizons.

In addition to the calibrating horizons, we also tracked several other strong continuous internal re- flections from KCS to $\mathrm{KCH}$. Although some horizons seem to be linked to similar characteristic peak patterns in the ice core records, it is not possible to clearly identify the causes of prominent reflections from comparison with ice core records alone (see discussion).

Table 3. Comparison of age-depth relation at borehole locations from ice core and GPR data

\begin{tabular}{llccccc}
\hline & & \multicolumn{2}{c}{ KCS } & & \multicolumn{2}{c}{ KCH } \\
\cline { 3 - 4 } \cline { 6 - 7 } Time & Event & Core & GPR & & Core & GPR \\
\hline 1977 & Dust & $23.2-23.7$ & 23.7 & & $11.5-11.9$ & 12.9 \\
1963 & Tritium & $31.1-31.9$ & 31.1 & & $16.3-16.6$ & 17.4 \\
1936 & Dust & $44.2-44.6$ & 44.5 & & $24.3-24.5$ & 25.3 \\
1902 & Dust & $55.5-55.8$ & - & & $33.8-34.1$ & - \\
\hline
\end{tabular}

Ice core data are taken from Armbruster (2000) and converted to depth below the 2000 surface using accumulation measurements and flow modeling (Keck, 2001). The depth of individual GPR reflector phases at $\mathrm{KCH}$ was determined as described in the text (cf. Fig. 4). 


\subsection{Application of the age-depth relationship}

The age-depth relation derived above uses information from $\mathrm{KCS}$ and $\mathrm{KCH}$. Additional estimates for the accuracy of the lateral transfer of the age-depth information can be performed with independent information available from the $\mathrm{CC}$ ice core, e.g. by comparing modeled burial depth since core retrieval with depths derived from fastening the dated $\mathrm{CC}$ records to the $\mathrm{KCS} / \mathrm{KCH}$ age-depth profiles.

The 1977 reference horizon is located $1.6-2.1 \mathrm{~m}$ below the top edge of the CC core and the 1902 signal at 26.3-26.5 m. According to accumulation measurements and flow modeling results, the 1977 signal submerged to a depth range of 11.0-11.2 m below the 2000 surface, while the 1902 reference horizon is at 30.5-30.6 m. Using the KCS/KCH/GPR age-depth relation, the lower limit of 1977 is $12.8 \mathrm{~m}$ (Fig. 4), and, accounting for the systematic error of $1 \mathrm{~m}$, the upper limit is $11.8 \mathrm{~m}$. As the 1902 layer is discontinous for some $50 \mathrm{~m}$, we cannot use it for tracking from KCS. From KCH the inferred depth of the 1902 layer at $\mathrm{CC}$ in 2000 is $31.8 \mathrm{~m}$. The resulting error interval $(5-15 \%)$ is mainly due to the uncertainties of the agedepth relationship $(\sim 1 \mathrm{~m})$ and the uncertainty in the absolute depth scale arising from the non-consolidated upper core sections, which are required for connection of the top of the core to the actual surface at time of drilling via snow-pit sampling.

\section{Discussion}

EM propagation wave speeds are one of the key properties to derive a true picture of the subsurface structure from GPR surveys. Comparison of wave speed-depth profiles derived from CMP survey data and ice-core properties from polar regions show that the agreement in a flat area can be within a couple of percent (Eisen et al., 2002). The larger discrepancies in our case, which are on the order of $10 \%$, are probably related to dipping of internal reflectors with respect to the surface, and to curved ray paths, which are neglected in the small spread approximation used here (Yilmaz, 1987).

Likewise, the inclination between surface and bedrock is probably the reason why the ice thicknesses determined at $\mathrm{KCH}$ is systematically smaller than borehole depth and core length. The two-dimensional (2D) migration performed during post-processing only corrects the dipping component which is parallel to the profile. As the subsurface and bedrock gradients are non-parallel to the profile lines in our case (Fig. 2) (i.e. out-of-plane) the bedrock dipping of around $7^{\circ}$ at $\mathrm{KCH}$ for profiles 2 and 3 relative to the surface implies that the depth is some $1.5 \%$ larger. To further improve the accuracy of the subsurface image, 3D survey setup and migration processing would be necessary. This requires, however, an extensive logistical and temporal effort during data acquisition (Moran et al., 2000).

Another issue to be considered when comparing GPR ice thicknesses is the nature of the bottom reflector. If crystalline rock is in direct contact with the glacier bottom, a sharp reflection could be expected. However, if a sedimentary layer is present, the reflected echo is more diffuse, thus increasing the error for ice thickness values. In our case, the bottom few metres of the ice cores all show entrainment of debris, although only at cores CC and KCS was the silty layer forming the ice-bedrock interface partly penetrated, although touch-down to bedrock is not definitely confirmed. We may now argue that the ice thickness from $\mathrm{KCH}$ borehole logging is underestimated by at least several decimetres relative to $\mathrm{CC}$ and $\mathrm{KCS}$ cores, since the CC-silty core fraction amounts to approximately $50 \mathrm{~cm}$, thus indeed adding to the uncertainty in the GPR ice thickness in comparison to borehole depths.

The internal structures of our radargrams are partially linked to ice thickness. This is expected, as the accumulation and flow field determine the submergence velocity, and thus the position of isochronic reflectors. Deep internal reflections towards KCS disappear, as the main flow channel of Colle Gnifetti is entered [for a radar cross-section of Colle Gnifetti see Lüthi (2000), Fig. A.4]. The matching of the age-depth profiles in the upper tens of metres between KCS and $\mathrm{KCH}$ by tracking internal reflections is encouraging. Errors are of the order of a wavelength, corresponding to a few years in the depth range under consideration. Different sources of errors were investigated for a comparable study in Svalbard by Pälli et al. (2002). Although the geophysical settings are somewhat different, their findings provide a good estimate of the general accuracy for combining ice-core profiles with radar data. As the uncertainties derived in this study are well within their error bars, we consider our results to be valid and representative for our study area.

Several features make it more diffcult to extend the transfer to larger depths: (i) the signal-to-noise ratio decreases in the vicinity of boreholes, probably because of the disturbed firn and ice structure, making 
it more difficult to separate internal reflections from noise; and (ii) the internal reflectors become more discontinuous with depth, especially where there is a larger inclination between reflector and surface. For instance, below approximately $25 \mathrm{~m}$ at KCS and $45 \mathrm{~m}$ at $\mathrm{KCH}$, no continuous internal reflections are detected. Either too much energy is absorbed during propagation below this level to detect a distinct return signal at the surface, or the ice properties change because of ice dynamics or post-depositional processes. The latter case is unlikely in the sense that flow features become irregular and disturb layering, as this would contradict age-depth relations established by Armbruster (2000) and Keck (2001) down to 40 and $70 \mathrm{~m}$ depth, respectively. However, physical and chemical properties show important transitions around these depths. Here, density reaches the value of glacier ice and melt layers are not outstanding anymore. Disregarding episodic mineral dust layers, the ice matrix chemistry changes from acidic to slightly alkaline properties due to much smaller emissions prior to 1950 (Fig. 5). Thus distinct acidic peaks can hardly be found below the critical depths. In general, decreasing variation in density would allow chemical horizons to become the primary reflection mechanism, but as both observed chemical and physical features reduce the overall reflection coefficient of distinct layers, the amount of energy reflected to the surface decreases as well.

To clearly identify the reason for missing reflectors in the lower part of the ice and to increase the accuracy of the age-depth transfer, the origin and structure of dominant reflectors have to be determined. Separating the effects of changes in density and chemical

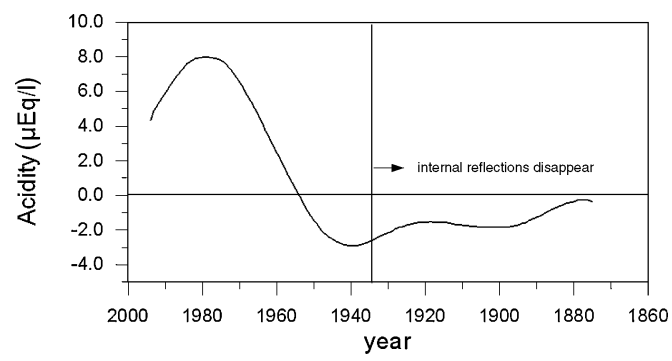

Fig. 5. General acidity trend analysed in the CC Colle Gnifetti ice core by direct measurements and ion balance evaluations. Outliers related to extreme saharan dust deposits were removed prior to SSA smothing. The vertical line at 1935 marks the approximate transition from continuous to discontinuous and finally disappearing internal GPR reflections, around $100 \mathrm{~m}$ from KCS (Fig. 4). composition, as well as determining the influence of variations of layer thickness on the recorded signal, can best be achieved by forward modeling of radargrams, based on DEP data (Eisen et al., 2003). Unfortunately, no DEP measurements were carried out after retrieving the ice cores.

In addition, forward modeling could be used to investigate the reasons for the vanishing of weaker phases when tracking horizons from KCS to $\mathrm{KCH}$, resulting in an improved understanding of the compisition of the reflection signals. So far one can argue that as layer thickness decreases by roughly $50 \%$ towards $\mathrm{KCH}$, it can be expected that the characteristics of internal reflectors change as well. This would have the important consequence that individual phases do not indicate isochronous surfaces. A bulk of phases, however, forming a distinguishable internal reflector, could be considered to correspond to a layer of distinct physical properties, extending over a small depth range, and thus being approximately isochronuous.

\section{Conclusions}

Internal reflections measured with GPR can be used to match and transfer age-depth relations of ice cores in cold alpine ice bodies over distances of at least several hundred metres. Successful application of GPR data requires, however, a smooth flow regime, the presence of strong continuous internal reflectors and a GPR system capable of recording weak reflections at high depth resolution. The GPR device should combine a powerful transmitter pulse with sub-metre resolution and large transmitter/receiver antenna gain. Given that GPR uncertainty is sufficently small, ice core interpretations profit from GPR surveys in several ways: (i) the age-depth relationships can be transferred from one site to another; (ii) interpretation of ambiguous peaks in core records can be complemented by matching clear signals from other cores via internal horizons; (iii) major transitions in physical-chemical properties can be remotely detected and continuously tracked to other parts of the region of interest; and (iv) the combination of surface measurements of ice velocity, modeling and reflection horizons at various depths provide a detailed picture of the 3D flow regime. Analyses of GPR surveys thus may help to assess upstream flow effects associated with strong longitudinal changes in the submergence velocity.

Despite the success of our study in the upper 30$50 \mathrm{~m}$ of the ice column at Colle Gnifetti, it fails to 
supplement the ice core age-depth relations and map the isochrone pattern at larger depth. Future radar activities at this site should therefore focus on the basal regime, being supported by high-resolution DEP if new ice cores are being retrieved. Power limitations can partly be overcome by decreasing the antennae frequency to $100 \mathrm{MHz}$ using the same GPR system, assuring lower absorption, sufficient resolution with a wavelength of $1.7 \mathrm{~m}$, and still managable operation. Remaining limitations are set by the absorption properties of ice and the working conditions at this highaltitude site.

Although the main reason for the limited sensitivity of the GPR data as well as the major ice properties leading to the observed GPR reflectors could not be unambiguously identified, we have demonstrated the value of including GPR in alpine glacier coring investigations. The glaciological characteristics of other cold alpine drill sites, e.g. in the Andes, Himalayas or north-west Canada, are not substantially different from Colle Gnifetti regarding geometry, firn fraction, melt layer occurence or mass balance. In this respect, they are expected to provide quite similar results in such GPR studies. On the other hand, (sub)tropical sites, which may experience much higher mineral dust but lower (anthropogenic) acid inputs may respond to potential acidic reflectors different to what is seen at Colle Gnifetti.

\section{Acknowledgments}

We are grateful for the invaluable logistic suport by Air Zermatt and the staff of Cabanna Regina Margherita from the Club Alpino Italiano di Varallo. Field work profited from advice and assisstance by Stephan Sutter; support from Guðfinna Tolly Aðalgeirsdottir greatly sped up field measurements. The comments and effort by Jack Kohler and two other anonymous reviewers helped to clarify the manuscript and are greatly acknowledged. The research was partially supported by the European Union Environment and Climate Programme under contract ENV4CT97-0639 (ALPCLIM) and the grant NI493/1 of the German Science Foundation.

\section{REFERENCES}

Alean, J., Haeberli, W. and Schädler, B. 1983. Snow accumulation, firn temperature and solar radiation in the area of the Colle Gnifetti core drilling site (Monte Rosa, Swiss Alps): distribution patterns and interrelationships. Z. Gletscherkd. Glazialgeol. 19, 131-147.

Armbruster, M. 2000. Stratigraphical dating of high-alpine ice cores over the last 1000 years (in German). Ph.D. Thesis, Ruprecht-Karls-Universität Heidelberg, Germany, http://archiv.ub.uni-heidelberg.de.

Bogorodsky, V., Bentley, C. and Gudmandsen, P. 1985. Radioglaciology, D. Reidel, Dordrecht.

Döscher, A., Gäggeler, H., Schotterer, U. and Schwikowski, M. 1995. A 130 years deposition record of sulfate and cloride from a high-alpine glacier. Water, Air, Soil Pollut. 85, 603-609.

Eisen, O., Nixdorf, U., Wilhelms, F. and Miller, H. 2002. Electromagnetic wave speed in polar ice: Validation of the CMP technique with high resolution DEP and $\gamma$-density measurements. Ann. Glaciol. 34, 150-156.

Eisen, O., Wilhelms, F., Nixdorf, U. and Miller, H. 2003. Identifying isochrones in GPR profiles from DEP-based forward modelling. Ann. Glaciol. 37 (in press).

Garotta, R. and Michon, D. 1967. Continuous analysis of the velocity function and the move out corrections. Geophys. Prospecting 15, 584-597.

Gudmandsen, P. 1971. Electromagnetic probing of ice. In: Electromagnetic probing in geophysics (ed. J. Wait), Golem Press, New York, 321-348.

Haeberli, W. and Funk, M. 1991. Borehole temperatures at the Colle Gnifetti core-drilling site (Monte Rosa, Swiss Alps). J. Glaciol. 37, 37-46.

Hempel, L., Thyssen, F., Gundestrup, N., Clausen, H. B. and Miller, H. 2000. A comparison of radio-echo sounding data and electrical conductivity of the GRIP ice core. J. Glaciol. 46, 369-374.

Keck, L. 2001. Climate significance of stable isotope records from Alpine ice cores. Ph.D. Thesis, Ruprecht-KarlsUniversität Heidelberg, Germany, http://archiv.ub.uniheidelberg.de.

Looyenga, H. 1965. Dielectric constant of heterogeneous mixtures. Physica 31, 401-406.

Lüthi, M. P. 2000. Rheology of cold firn and dynamics of a polythermal ice stream. Mitteilungen, Versuchsanstalt für Wasserbau, Hydrologie und Glaziologie der ETH Zürich, vol. 165.

Maupetit, F., Wagenbach, D., Weddeling, P. and Delmas, R. 1995. Recent chemical and isotopic properties of high altitude cold Alpine glaciers. Atmos. Environ. 29, 1-9.

Millar, D. H. H. 1981. Radio echo layering in polar ice sheets and past volcanic activity. Nature 292, 441-443.

Moore, J. and Paren, J. 1987. New technique for dielectric logging of Antarctic ice cores. J. Phys. (Colloq. C1) 48, 155-160.

Moran, M. L., Greenfield, R. J., Arcone, S. A. and Delaney, A. J. 2000. Delineation of a complexly dipping temperate glacier bed using short-pulse radar arrays. J. Glaciol. 46, 274-286. 
Murray, T., Stuart, G. W., Miller, P. J., Woodward, J., Smith, A. M., Porter, P. R. and Jiskoot, H. 2000. Glacier surge propagation by thermal evolution at the bed. J. Geophys. Res. 105, 13 491-13 507.

Pälli, A., Kohler, J. C., Isaksson, E., Moore, J. C., Pinglot, J. F., Pohjola, V. A. and Samuelsson, H. 2002. Spatial and temporal variability of snow accumulation using groundpenetrating radar and ice cores on a svalbard glacier. $J$. Glaciol. 48, 417-424.

Preunkert, S., Wagenbach, D., Legrand, M. and Vincent, C. 2000. Col du Dôme (Mt. Blanc Massif, French Alps) suitability for ice cores studies in relation with past atmospheric over Europe. Tellus 52B, 993 1012.

Preunkert, S., Legrand, M. and Wagenbach, D. 2001. Sulfate trends in a Col du Dôme (French Alps) ice core: a record of anthropogenic sulfate levels in the European midtroposphere over the 20th century. J. Geophys. Res. 106, 31 991-32004.

Robin, G. de Q., Evans, S. and Bailey, J. T. 1969. Interpretation of radio echo sounding in polar ice sheets. In: Philos. Trans. R. Soc. London Ser. A 146, 437-505.

Shumskii, P. A. 1964. Principles of structural glaciology: the petrography of fresh-waterice as a method of glaciological investigation. Dover, New York.

Siegert, M. 1999. On the origin, nature and uses of Antarctic ice-sheet radio-echo layering. Prog. Phys. Geog. 23, 159179.

Suter, S. 2002. Cold firn and ice in the Monte Rosa and Mont Blanc areas: spatial occurrence, surface energy balance and climatic evidence. Mitteilungen, Versuchsanstalt für
Wasserbau, Hydrologie und Glaziologie der ETH Zürich, vol. 172.

Vincent, C., Vallon, M., Pinglot, F., Funk, M. and Reynaud, L. 1997. Snow accumulation and ice flow at Dôme du Goûter (4300 m), Mont Blanc, French Alps. J. Glaciol. 43, 513521 .

Wagenbach, D. 1989. Environmental records in alpine glaciers. In: The environmental record in glaciers and ice sheets, Dahlem Konferenzen, John Wiley and Sons, Chichester, 69-83.

Wagenbach, D. 1994. Special problems of mid latitude glacier ice core research, In: Greenhouse gases, isotopes and trace elements in glaciers as climatic evidence for the Holocene, Report of the ESF/EPC Workshop, Zürich, 27-28 October 1992, Arbeitsheft No 14, VAW-ETH Zürich, Switzerland, $10-14$.

Wagenbach, D., Preunkert, S., Schäfer, J. and Jung, W. 1996. Northward transport of Saharan dust recorded in a deep Alpine ice core. In: The impact of African dust across the Mediterranean, Kluwer Academic Publishers, Dordrecht, 291-300.

Wagner, S. 1996. Three-dimensional modeling of two glaciers and deformation analysis of ice-rich permafrost (in German). Mitteilungen, Versuchsanstalt für Wasserbau, Hydrologie und Glaziologie der ETH Zürich, vol. 146.

Wilhelms, F. 2000. Measurement of dielectric properties of polar ice cores (in German). Berichte zur Polarforschung, Alfred-Wegener-Institut für Polar- und Meeresforschung, vol. 367.

Yilmaz, O. 1987. Seismic data processing. Investigative Geophysics, Society of Exploration Geophysicist, vol. 2. 